\title{
Estimating a Health Production Function for Brazil: Some New Evidence
}

\author{
Pedro Hemsley ${ }^{1}$ Lavinia Hollanda ${ }^{2}$ \\ ${ }^{1}$ Institute of Economics, Federal University of Rio de Janeiro, Rio de Janeiro, Brazil \\ ${ }^{2}$ Escopo Energia, Rio de Janeiro, Brazil \\ Email: pedro.hemsley@ie.ufrj.br
}

How to cite this paper: Hemsley, P., \& Hollanda, L. (2020). Estimating a Health Production Function for Brazil: Some New Evidence. Theoretical Economics Letters, 10, 1073-1092.

https://doi.org/10.4236/tel.2020.105063

Received: September 3, 2020

Accepted: October 13, 2020

Published: October 16, 2020

Copyright (c) 2020 by author(s) and Scientific Research Publishing Inc. This work is licensed under the Creative Commons Attribution International License (CC BY 4.0).

http://creativecommons.org/licenses/by/4.0/

\begin{abstract}
This paper reports the impact of low-cost health centers on child mortality in Brazil. We use a comprehensive database to evaluate the impact of a change in Brazilian health policy from 2006 to 2009, when the number of health centers per capita increased significantly while hospitals per capita were reduced, indicating a focus on low-cost, low-complexity medical services. Unlike most empirical studies, our results indicate that additional health care decreases mortality. Increasing the number of health centers per capita decreases mortality through access to basic services and make high-complexity hospitals more effective, as they can focus on more serious conditions.
\end{abstract}

\section{Keywords}

Health Care Economics and Organizations, Health Expenditures, Child Mortality

\section{Introduction}

Medical care expenditures have been rising rapidly in most countries. According to the World Bank (2020), total health expenditure in Brazil grew from 8.3\% of Gross Domestic Product (GDP) in 2000 to $9.5 \%$ in 2017. This increase has come both from the private and the public sectors: public health expenditure increased from $3.5 \%$ in 2000 to $4 \%$ in 2017 , accounting for more than $40 \%$ of total health expenditure. This upward trend is expected to continue, as most developed countries have even higher (and still increasing) percentages of GDP dedicated to health. For a comparison, in the United States, this share rose from $12.5 \%$ in 2000 to $16.4 \%$ in 2010 and $17.1 \%$ in 2017. In France, it went from 9.6\% in 2000 to $11.3 \%$ in 2017; in Germany, in the same period, it increased from $9.8 \%$ to $11.2 \%$. 
A recurrent policy question is whether higher health expenditure actually improves the health status of the population. Several empirical studies present a negative answer. Thornton (2002) finds that medical care expenditures have no impact in American states, confirming earlier studies such as Auster et al. (1972). In developing countries, evidence is even harsher: health care expenditure has a negative impact on life expectancy, since it may be squeezing out more valuable inputs such as food or water ${ }^{1}$.

This paper revisits this issue by investigating the relationship between the age-specific mortality rate of children up to 5 years old and the availability of low-cost health centers. This rate is defined as the ratio between the number of deaths of individuals under five years old and the population of that age in each year. (Formally, it is not the same as the under-five mortality rate, which is the ratio between the number of deaths in this age range per 1.000 births, although both measures capture the death risk of under-five children.) The main reason to choose child mortality is that children are particularly sensitive to health care. Moreover, lower child (and infant) mortality rates have significant impacts on a populations life expectancy. Generally, most concepts used to evaluate the benefits of medical interventions take into account how many years patients are expected to live after the intervention, highlighting the importance of child care (the concept of disability-adjusted life years ${ }^{2}$ ). We restrict our attention to mortality due to diseases, as opposed, for example, to deaths due to violence or accidents.

With a child mortality rate of 20.6 per 1000 in 2009, Brazil performed poorly even when compared to countries with lower levels of income per capita (Colombia, for instance, had 19.7 in 2000) and to other Latin American countries (Mexico 17.6, Argentina 14.2 and Chile 8.9 in the same year), according to the World Bank ${ }^{3}$-see Table 1 for details. This is most surprising considering that Brazil spends more on health as a share of GDP than many countries with higher per capita income, such as Chile (8.2\%), Russia (5.4\%) and Mexico (6.5\%)-all of which were able to attain much lower child mortality rates. Again, this suggests that lack income is not the main restriction in Brazil.

These figures strongly suggest misdirected health expenditures. Brazil had an underfunded health system for a long time. Also, the country invested in expensive hospitals instead of simpler centers able to treat minor conditions effectively and prevent them from becoming serious (and demanding expensive treatments). These factors resulted in an inefficient health structure.

In spite of these weak comparisons, both infant and child mortality rates in Brazil have been declining consistently. The age-specific mortality rate for the under-five population declined from 4.6 in 2002 to 3.7 in 2009 (per 1000 children at this age) - a reduction of $20 \%$.

${ }^{1}$ See Fayissa and Gutema (2005) for an estimation of a health production function in Sub-Saharan Africa.

${ }^{2}$ See Murray (1994).

${ }^{3}$ World Bank (2020). 
Table 1. Infant and Under-Five Mortality (per 1.000 live births): Brazil and Similar Countries (2009).

\begin{tabular}{|c|c|c|c|}
\hline Country & $\begin{array}{c}\text { Infant Mortality } \\
\text { Rate }^{\mathrm{a}}\end{array}$ & $\begin{array}{c}\text { Under-Five } \\
\text { Mortality Rate }{ }^{\mathrm{b}}\end{array}$ & $\begin{array}{c}\text { GDP per capita } \\
\text { (constant } 2005 \text { US\$) }\end{array}$ \\
\hline Argentina & 12.7 & 14.2 & 13.272 \\
\hline Brazil & 18.4 & 20.6 & 9.438 \\
\hline Chile & 7.7 & 8.9 & 13.044 \\
\hline China & 16.8 & 19.6 & 6.206 \\
\hline Colombia & 17.1 & 19.7 & 8.251 \\
\hline Mexico & 14.9 & 17.6 & 11.951 \\
\hline Russia & 9.8 & 12.5 & 13.623 \\
\hline
\end{tabular}

${ }^{\mathrm{a}}$ Number of infants dying before reaching one year of age, per 1.000 live births in a given year; ${ }^{\mathrm{b}}$ Probability per 1.000 that a newborn will die before age 5 , if subject to age specific mortality rates; Sources: World Health Organization and World Bank.

The modern Brazilian Health System (abbreviated in this paper to BHS) was implemented in 1990, with the creation of SUS (the Unified Health System), a comprehensive health system that articulates funding and policies from federal, state and local governments. It was designed after the UK health system: universal and state-funded and, therefore, very expensive. However, after the creation of SUS, Brazil faced another four years of extreme macroeconomic instability and unsoundly managed public finance, and the new system remained underfunded during this period.

From 1995 on, health funding began increasing systematically (although funding has been mostly federal, local governments can add funds and direct policy, so that policy is not homogenous). In practical terms, this amounted to a large and continuous extension of health services. Nevertheless, the very nature of the BHS-perfect insurance, which induces systematic overuse-made funding permanently insufficient. This caused policymakers to search for cheap solutions: in order to improve access to basic and preventive care, health policy aimed to significantly increase the number of low-cost, low-complexity health centers across the country, at the expense of major hospitals.

Child mortality reflects mostly prenatal care and newborn care, as most under-five deaths occur in the first year (86\% in Brazil in 2008). There has been significant evolution in newborn care due to new technologies, but it is still very expensive: it is usually devoted to low-weight/preterm births, which usually demand delicate treatments as thoroughly discussed in Currie and Gruber (1996). Additionally, surviving low-weight babies face a high risk of major handicaps that will mean both severe restrictions and high medical expenditures through-out life. To decrease the number of such cases, policy has shifted towards prevention of low-weight/preterm births through prenatal care. Clinical evidence solidly suggests prenatal care reduces low-weight births and infant mortality (even 
when corrected for possible selection bias), and is more cost-effective than neonatal care-see Gabbe et al. (2016) for a discussion. There are different types of centers, but we pool them together since they usually do not have major differences in service capacity, and treat both pregnant women and children (some are specific to maternity, but they are roughly substitutes since a new center reduces waiting times in others).

In short, one of the main objectives of increasing the number of health centers in Brazil since the 1990s was to offer prenatal care, which can be offered in low-cost health centers as it is relatively cheap and simple, and hence reduce infant mortality at an affordable cost. This policy was particularly active between 2006 and 2009, the period we analyze: health centers per 1000 people increased nationwide: from 0.32 in 2005 to 0.40 in 2009-an increase of more than $20 \%$ in only four years, while the number of hospitals relative to the population decreased by $2.5 \%$ in the same period. The total number of these health centers increased from 59,634 to 75,799 in the same period, a significant $27 \%$ increase, while hospitals increased by only $1.3 \%$ (source: DataSus, a broad health database made available by the Brazilian Health Ministry).

In our analysis, we were able to identify the impact of changes in the availability of health centers due to the fact that these changes were strongly diversified across states. While in some states it increased up to $40 \%$ in the four-year period under study, in others it decreased by as much as $25 \%$, suggesting either different health policies were being implemented, or public expenditures on health were limited (an exceptional situation given the national trend discussed above). We use health data for the period 2006 to 2009 from DataSus to evaluate the evolution of different health centers per capita in every state, building an aggregate measure of nearly-substitute centers. We then evaluate the impact of these changes on child mortality, one of the main indicators of child health. We choose this period for two main reasons. First, as mentioned, this substitution policy (hospitals for health centers) was particularly active. Second, due to the availability of data, as the measurement of some series we use was changed afterwards. We have two main results, discussed in detail in section 3: additional health centers per capita reduce child mortality (direct effect) and make hospitals more effective (indirect effect).

Although this is an empirical paper, there is a long tradition in the theoretical literature that provides foundations for $\mathrm{it}^{4}$. While we do not intend to cover that tradition here, it is worth mentioning that we are building on the concept of aggregate health production function, originally developed by Grossman (1972). Individuals use different inputs to produce health: medical services, income, and education, among others. Notice that in order to apply this to child mortality, one must assume parents are making the best choices from the point of view of their children. Also, population-related characteristics refer to the whole of society, and exclude pre-school children themselves-who do not earn any income 
or have any level of education. Hence we are controlling for the impact of adult features on infant health, not the impact of an individual's features on his or her own health, as suggested by aggregate health production functions. In short, we evaluate how these features affect the way parents take care of their children. Lastly, although the focus of the paper is to study the impact of health structure on child mortality, it is well known that health policy is not the only policy that affects health outcome. In particular, educational and income policies are believed to have a large impact on health.

The BHS's full coverage is equivalent to complete insurance for public health: income is decreased through taxes and is reverted as free health services. Hence, a moral hazard problem arises: people have lower incentives to avoid risky behavior (ex-ante) and to take good care of an illness (ex-post). As a result, the BHS tends to amplify demand, as prices are not the restriction. The actual restriction comes from long lines and the unavoidable low quality of overused medical services (in fact, individuals also buy partial private insurance to overcome these issues). Hence, building a new health center is less effective than if people had more income but had to pay medical fees. For this reason, we interpret the results below as a lower bound on the effect of health centers on child mortality.

The remainder of the paper is organized as follows. In Section 2 we discuss our methodology. Section 3 presents the results. Section 4 concludes. The appendices collect all tables and provide a detailed description of the data.

\section{Data and Methodology}

We evaluate the impact of changes in the availability of public health centers on child mortality outcomes. We use annual aggregate data from DataSus and IBGE for the 27 Brazilian states in the years 2006 to 2009. The DataSus provides comprehensive information on the human and physical health infrastructure available in the country, both public and private, disaggregated by the type of facility (hospitals, health centers and other types of health facilities) and medical specialization.

We use health units (per 1000 inhabitants, like all the other measures) instead of health expenditures because it allows us to make use of more detailed series: expenditures series are more aggregated. However, we are pooling together different types of institutions. We believe this should not create any major distortions as these institutions have similar capacities for medical interventions and, more importantly, can be viewed as nearly substitutes: one more unit will decrease the number of people that go to the other ones looking for same basic services provided in any of them. For the information on child mortality $(0-4$ years), we used the information for general mortality by age also available in DataSus; and for population by age, from IBGE.

Our empirical strategy is to regress these state/year outcomes for child mortality on the number of health centers relative to the population of each state. We ask the question: as the number of health centers per capita increases, does 
child mortality fall? As discussed in the previous sections, the dependent variable is the age-specific mortality rate of under-five children and the main regressor is the number of health centers per 1000 inhabitants. We include several controls, discussed below-see Table 2 for some descriptive statistics for the variables we used, which are detailed in the Appendix.

A first potential drawback for this empirical strategy is related to the direction of causality. On the one hand, we expect more health centers to decrease child mortality; on the other hand, public health policy is addressed primarily at states with high mortality rates, which should invert the expected sign of the estimated coefficient. While we tested a number of different instruments with similar results (so that the model was not oversensitive to the choice of instruments), we use the one-period lag of health centers per capita as our main instrument. First, it is highly correlated to the current value of health centers, as the series presents significant inertia. Second, it should not respond to future unexpected changes of child mortality.

This implies we are ruling away time-persistent effects: only current values affect child mortality. Moreover, we rule away dynamic effects (lagged values of mortality itself). For example, it does not matter if there was no health center available in the previous year if there is one now (there is no "habit formation"; pregnant women and parents of newborns will use any health services available if they need to). Since most under-five deaths happen in the first year, we understand this is not a very restrictive assumption. The only delicate point for this assumption to hold is related to the health of pregnant women: if the health of a newborn or young child depends significantly on the health of the mother before the pregnancy, which in turn depends on the availability of health centers in the past, then some of our instruments may be weak. However, research indicates that the health of the mother during pregnancy is much more important to the health of the newborn than health before pregnancy (Gabbe et al., 2016).

Table 2. Descriptive statistics.

\begin{tabular}{cccccc}
\hline Variable & Mean & Median & Max & Min & St. Dev. \\
$\begin{array}{c}\text { Education } \\
\text { (\% up to 4 years) }\end{array}$ & 0.6641 & 0.6728 & 0.9812 & 0.3497 & 0.1283 \\
Private Coverage (\%) & 0.1266 & 0.0930 & 0.4030 & 0.0290 & 0.0860 \\
Share of smokers (\%) & 0.1534 & 0.1525 & 0.2250 & 0.0800 & 0.0302 \\
$\begin{array}{c}\text { Share of population with } \\
\text { garbage collection (\%) }\end{array}$ & 0.7398 & 0.7564 & 0.9662 & 0.2681 & 0.1241 \\
Income (\% of poor) & 0.3440 & 0.3521 & 0.6739 & 0.0636 & 0.1614 \\
$\begin{array}{c}\text { Share of population in } \\
\text { urban areas (\%) }\end{array}$ & 0.7536 & 0.7944 & 0.9821 & 0.0000 & 0.2038 \\
$\begin{array}{c}\text { Immunization (\%) } \\
\text { Imm }\end{array}$ & 0.7825 & 0.7820 & 0.9278 & 0.6062 & 0.0607 \\
\hline
\end{tabular}

Sources: DataSus, IBGE, Vigitel and Ipea Data. 
Nevertheless, if the use of lagged value is not completely effective at dealing with the endogeneity issue, the direction of the bias is positive (as higher mortality rates induce policymakers to increase the number of health centers); hence our estimators will be lower (in absolute value) than the true parameter and the probability of rejecting the null hypothesis will also be lower. In other words, our model underestimates the impact of health centers on child mortality. A similar reasoning applies to the other health-related variables in the model (discussed below): we assume the explanatory variables have no cumulative effect.

In order to avoid a possible problem caused by omitted variables, we bring into the model a series of control variables suggested by other empirical papers and by the theoretical literature. ${ }^{5}$ The first control variable is income. As suggested by Grossman (1972), a higher income may be used to afford medical services and hence improve health outcomes. While in Brazil individuals cannot directly buy access to the public health system (due to the perfect-insurance structure of the BHS), they could potentially use their income to buy either private medical services, or other complementary goods and services related to improved health.

Although we do check different income measures, we focus on the proportion of poor in the population (defined as household per capita income lower than the poverty line, as discussed in the Appendix) because the impact of income is not linear: additional income improves health since individuals become able to afford significant inputs for health production (sanitation and nutrition are common examples). However, a higher income may be the result of work overload. The former effect should be dominant when income levels are very low, as demand is inelastic for basic services. Therefore we expect a positive sign: the higher the proportion of low income people in a society, the higher mortality rates should be.

Income also suffers from the same endogeneity problem as health services (Grossman, 2017): reversed causality. While more income may be used to improve health, better health also enables an individual to earn more income (say, higher productivity or more workhours). In relation to child mortality, this means parents of healthy children will have higher income. Again, the main instrument we use is the lagged value of income, which is strongly related to present income but cannot respond to present child mortality: accumulated income (from one year to the next) has no effect. We think this is reasonable for poor people, who hardly have any savings.

We also include the share of the population with private insurance as a control for access to private health services. We expect it to decrease mortality rates and to be correlated both with income and with the availability of public health structure. For the same reason our measure of health centers is endogenous, so should private insurance be: people tend to hire more insurance when they (or

${ }^{5}$ Again, we reference the reader to Zweifel et al. (2009) for an overview and to Grossman (1972) for the seminal contribution. 
their children) have poor health. Analogously, we use the lagged value of this share as our instrument. We also include the share of the population with private insurance as a control for access to private health services. We expect it to decrease mortality rates and to be correlated both with income and with the availability of public health structure. For the same reason that our measure of health centers is endogenous, so should private insurance be: people tend to hire more insurance when they (or their children) have poor health. Analogously, we use the lagged value of this share as our instrument.

The third control is education. As suggested by numerous works, it has a large impact on health. Again, in spite of checking different measures, we focus on the proportion of the population with four or less years of formal schooling. Theoretical models suggest more educated societies are more efficient at health production (Grossman, 1972): they have more knowledge on prevention and treatments, parents are more suited to take care of infants and children. Notice also that most health-related knowledge is provided in basic education (it does not rise significantly whether one has 8 or 12 years of schooling). Hence we use the proportion of the population with four or less years of schooling as our measure of education. We expect a positive sign: the higher the proportion of uneducated people, the higher mortality rates should be.

It is not clear whether education also suffers from endogeneity. For example, the theoretical model of Grossman (1972) does not suggest it should be so. However, human capital models indicate parents decide to spend more on educating their children if they expect a higher survival rate (Lucas Jr., 1988), implying again a reversed causality problem. While this is probably relevant in the long run, we assume it is not important regarding child mortality, as educational decisions are usually made after children have survived past any relevant thresholds (one or five years of age).

However, a possible problem of omitted variables might be a relevant source of endogeneity for education. In particular, public investment in education might be correlated with other policies aimed at reducing child mortality (different from health centers). Instead of using an instrument for education, we choose to correct this bias by introducing a political variable in the model: a dummy that equals one when the same political party (or coalition) is in office both at federal level (president) and state level (governor). It is well-known that there is a strong bias in transferring federal funds to allied parties. This dummy should capture the effect of other public investments aimed both at reducing child mortality and improving education. Notice we do not include any variable for different political parties, as we assume there is no difference in the political spectrum that might lead to significant differences in public investment. The relevant issue is how close a state is to federal funds, not ideology.

An important issue concerns the role of other public health policies aimed at reducing child mortality. To the extent that they may be correlated to the implementation of health centers, our coefficients may be biased. We understand 
that the development of health care centers is an encompassing policy under which specific programs are implemented, so that we are capturing, in a non-specific way, most policies. One of the main policies not captured is the construction of hospitals, which is exactly what is being avoided through health centers. Hence, we include the number of hospitals per 1,000 inhabitants. Moreover, we expect hospitals and health centers to have a strong interaction: the latter offers low-cost, low-complexity services, leaving room for the former to focus on high-complexity services. For this reason we also include an interaction term between hospitals and health centers.

One specific caveat comes from the type of physician made available at different points. While we still do not have conclusive results on it, we will mention it in section 4 below. We also include immunization coverage, as one of the main deterrents of major conditions.

Other controls are the share of white people in the population, the share of smokers, the proportion of the population in urban areas, and the percentage of households with access to direct garbage collection. White people have historically enjoyed better public services in Brazil. Smoking may only have an indirect impact, as legally children cannot smoke. However, there is an indirect impact through parents and community. Population in urban areas does not have a straightforward sign, but we expect it to be negative (decrease mortality) as cities usually have a better health structure. ${ }^{6}$ It is also related to the concentration of the population, which benefits from economies of scale in health services. Garbage collection is a measure of quality of sanitation services. We expect a negative sign, as sanitation is supposed to improve health (sanitation series have recently been discontinued, and we use direct garbage collection as a substitute.). Lastly, notice that by choosing shares of the population we avoid dealing with possibly integrated series.

As mentioned in the introduction, health and educational policies do not act independently. First, the more educated people are, the more they will know how to use health services (and to follow received instructions). Second, efficient health services avoid family-disruptive events that prevent school-age children from attending school. In order to capture these effects, we include the interaction between health centers and education as a regressor.

Since we have panel data, one relevant point is the structure of potential unobserved fixed state effects. We do not assume them away. However, we assume they are uncorrelated with the time-varying regressors. In this case, a random-effect model is the most appropriate: fixed-effect estimators are inefficient and OLS test statistics will be incorrect. We will apply it throughout the next section, and come back to this topic in the last section.

\section{Results}

Our main results are reported, in terms of elasticities, in Table 3 (with no cor${ }^{6}$ See Glaeser (2011). 
rection for endogeneity) and Table 4 (estimated by two-stage least squares). Our prime interest is in column 3 , estimated with the random effects method.

Notice initially that point estimates in Table 3 are systematically lower than in Table 4, reflecting the reverse causality problem: endogeneity biases the estimated coefficients of health centers and hospitals towards zero, since the impact of child mortality on health expenditures should be positive, while we expect both variables to have a negative coefficient. The coefficient of health centers, for example, is three times lower in Table 3, columns 2 (fixed effects) and 3 (random effects): in absolute value, they go from 0.7 to more than 2 - this is a large effect and suggests there is room for improvement considering the disparity of health centers per capita in our sample (it ranges from only 0.21 to 0.72 ). ${ }^{7} \mathrm{We}$ interpret this as evidence that results in Table 4 underestimate the actual impact of health centers and hospitals if the proposed instruments are not sufficient to eliminate endogeneity, as far as its main cause is reverse causality. We are then implicitly assuming that preferences for health are stable in short period of times such as our four-year span, as otherwise changes in preferences could be a source of endogeneity different from reversed causality.

Comparing the first three columns of Table 4, one can see that random effects (RE) and fixed effects (FE) estimators are quite close. The estimated impact of health centers are, respectively, -2.16 and -2.33 , while the OLS estimator is only -1.02 . In the case of hospitals, these values are $-1.08,-1.00$ and -0.23 . This suggests that, as assumed, unobserved fixed effects are not correlated with time-varying regressors; the next section revisits this point.

The RE coefficients of health centers and hospitals are, as expected, negative and significant. Moreover, the former is much larger in absolute value: -2.16 against -1.08 . This suggests low-complexity treatments on a large scale are more relevant to reduction of child mortality than high-complexity treatments on a small scale. This is particularly striking when one considers that hospitals are much more expensive and offer more sophisticated services, as discussed in the previous sections.

The interaction between health centers and hospitals is also negative, as expected, and significant. Interpretation is straightforward: the higher the number of health centers (hospitals), the larger the impact of hospitals (health centers) on child mortality. Although we cannot tell the direction of causality, this result confirms the idea that health centers and hospitals are complementary: low-complexity centers should not be responsible for high-complexity cases; more surprisingly, the opposite should not hold either. Taking the cross-effect into account, the average impacts of health centers and hospitals are, respectively, -2.20 and -1.35 . Square terms were not significant in any specification of the model, suggesting Brazil has not yet reached decreasing returns.

Notice that if the interaction term is dropped from the model (column 4 in Table 4), both variables lose significance. This is in line with the interpretation ${ }^{7}$ See Table 2. 
Table 3. Regression results (No instruments).

\begin{tabular}{|c|c|c|c|c|c|}
\hline $\begin{array}{l}\text { Dependent Variable: Child } \\
\text { Mortality }(0-4 \text { years })\end{array}$ & (1) & (2) & (3) & (4) & (5) \\
\hline \multirow{2}{*}{ Health Centers } & $-0.831013^{\star *}$ & 0.784381 & -0.716013 & -0.181353 & -0.546944 \\
\hline & $(0.356794)$ & -1.822991 & -1.005997 & $(0.112193)$ & -1.016542 \\
\hline \multirow{2}{*}{ Hospitals } & $-0.250118^{\star *}$ & 0.735214 & -0.235888 & -0.07161 & -0.294253 \\
\hline & $(0.107585)$ & $(0.687781)$ & $(0.330611)$ & $(0.058997)$ & $(0.29556)$ \\
\hline \multirow{2}{*}{$\begin{array}{c}\text { Interaction (Health } \\
\text { Centers and Hospitals) }\end{array}$} & $-0.209224^{\star *}$ & 0.328722 & -0.157169 & - & -0.204781 \\
\hline & $(0.097393)$ & $(0.561082)$ & $(0 . .281792)$ & & $(0.252247)$ \\
\hline \multirow{2}{*}{$\begin{array}{c}\text { Interaction (Health } \\
\text { Centers and Education) }\end{array}$} & - & - & - & - & $0.608699^{*}$ \\
\hline & & & & & $(0.33449)$ \\
\hline \multirow{2}{*}{ Income } & -0.005962 & -0.094617 & -0.020523 & -0.0228 & -0.021422 \\
\hline & -0.015962 & -0.095801 & -0.046589 & -0.047661 & -0.042215 \\
\hline \multirow{2}{*}{ Private Coverage } & $-0.086701^{\star * \star}$ & -0.068841 & -0.110656 & $-0.115651^{*}$ & $-0.152666^{\star *}$ \\
\hline & -0.030025 & -0.089756 & -0.070272 & -0.067116 & -0.064742 \\
\hline \multirow{2}{*}{ Education } & $0.132555^{\star *}$ & 0.026572 & 0.014685 & 0.00515 & $0.50336^{*}$ \\
\hline & -0.053982 & -0.223403 & -0.094233 & -0.094054 & -0.297584 \\
\hline \multirow{2}{*}{$\begin{array}{l}\text { Share of white } \\
\text { population }\end{array}$} & $-0.297236^{* * *}$ & $-0.295568^{* * *}$ & $-0.2485^{\star *}$ & $-0.248714^{* *}$ & $-0.239684^{* *}$ \\
\hline & -0.065343 & -0.086878 & -0.100416 & -0.098283 & -0.095492 \\
\hline \multirow[t]{2}{*}{ Share of smokers } & $0.150504^{* * *}$ & $0.114176^{* *}$ & $0.128072^{\star \star}$ & $0.124933^{* *}$ & $0.132617^{* * *}$ \\
\hline & -0.044882 & -0.056593 & -0.050169 & -0.05075 & -0.048913 \\
\hline \multirow{2}{*}{$\begin{array}{l}\text { Share of population in } \\
\text { urban areas }\end{array}$} & $0.247018^{\star}$ & $1.678355^{\star}$ & 0.190996 & 0.218167 & 0.252927 \\
\hline & -0.129768 & -0.940852 & -0.327531 & -0.290074 & -0.323189 \\
\hline \multirow{2}{*}{$\begin{array}{l}\text { Share of population with } \\
\text { garbage collection }\end{array}$} & 0.039772 & 0.222085 & 0.24335 & 0.241685 & $0.270814^{*}$ \\
\hline & -0.123896 & -0.142826 & -0.158346 & -0.161881 & -0.156332 \\
\hline \multirow{2}{*}{ Political Dummy } & 0.02521 & 0.029374 & 0.024236 & 0.021513 & 0.013351 \\
\hline & -0.018075 & -0.035166 & -0.03297 & -0.02924 & -0.036302 \\
\hline \multirow{2}{*}{ Vaccine } & -0.543554 & $1.069537^{* * *}$ & 0.668449 & 0.653134 & 0.587343 \\
\hline & -0.441443 & -0.370613 & -0.402582 & -0.403923 & -0.379393 \\
\hline Year Effects & $\mathrm{x}$ & $\mathrm{x}$ & $\mathrm{x}$ & $\mathrm{x}$ & $\mathrm{x}$ \\
\hline Fixed Effects & & $\mathrm{x}$ & & & \\
\hline Random Effects & & & $\mathrm{x}$ & $\mathrm{x}$ & $\mathrm{x}$ \\
\hline Number of observations & 105 & 105 & 105 & 105 & 105 \\
\hline
\end{tabular}

Note: robust standard error in parentheses. ${ }^{* *},{ }^{* *}$ and ${ }^{\star}$ denote significance at $1 \%, 5 \%$ and $10 \%$ respectively. All variables in logarithm except "Political Dummy". The constant term is always included. No instruments included. 
Table 4. Regression results (Instrumental Variables: Lagged Values).

\begin{tabular}{|c|c|c|c|c|c|}
\hline $\begin{array}{l}\text { Dependent Variable: Child } \\
\text { Mortality }(0-4 \text { years })\end{array}$ & (1) & (2) & (3) & (4) & (5) \\
\hline \multirow{2}{*}{ Health Centers } & $-1.026913^{\star *}$ & -2.336175 & $-2.167827^{\star}$ & 0.323635 & -2.337599 \\
\hline & -0.425789 & -3.495448 & -1.235531 & -0.572859 & -1.425554 \\
\hline \multirow{2}{*}{ Hospitals } & $-0.234296^{\star *}$ & -1.000066 & $-1.084843^{\star *}$ & -0.562236 & $-1.100655^{\star * *}$ \\
\hline & -0.114206 & -2.190815 & -0.460112 & -0.475308 & -0.391636 \\
\hline \multirow{2}{*}{$\begin{array}{l}\text { Interaction (Health } \\
\text { Centers and Hospitals) }\end{array}$} & $-0.268078^{\star *}$ & -0.694619 & $-0.671503^{*}$ & - & $-0.838149^{* *}$ \\
\hline & -0.115403 & -1201474 & -0.343376 & & -0.329578 \\
\hline \multirow{2}{*}{$\begin{array}{c}\text { Interaction (Health } \\
\text { Centers and Education) }\end{array}$} & - & - & - & - & 0.950955 \\
\hline & & & & & -0.881027 \\
\hline \multirow{2}{*}{ Income } & 0.008926 & 1.022684 & 0.005654 & -0.008133 & 0.017811 \\
\hline & -0.016025 & -1037085 & -0.064526 & -0.087452 & -0.054508 \\
\hline \multirow{2}{*}{ Private Coverage } & -0.049295 & 0.005272 & -0.029253 & 0.037893 & -0.087784 \\
\hline & -0.02965 & -0.382848 & -0.162287 & -0.284451 & -0.184834 \\
\hline \multirow{2}{*}{ Education } & $0.239008^{* * *}$ & 0.387046 & -0.132324 & -0.268207 & 0.749621 \\
\hline & -0.074411 & -0.304771 & -0.310246 & -0.390925 & -0.781876 \\
\hline \multirow{2}{*}{$\begin{array}{l}\text { Share of white } \\
\text { population }\end{array}$} & $-0.375095^{* * *}$ & -0.374964 & -0.143898 & -0.145547 & $-0.229433^{\star *}$ \\
\hline & -0.065952 & -0.24069 & -0.191782 & -0.275123 & -0.112261 \\
\hline \multirow{2}{*}{ Share of smokers } & $0.13746^{* *}$ & $0.240759^{* *}$ & 0.1493 & 0.118292 & $0.140147^{\star \star}$ \\
\hline & -0.05403 & -0.11703 & -0.095605 & -0.151608 & -0.063893 \\
\hline \multirow{2}{*}{$\begin{array}{c}\text { Share of population in } \\
\text { urban areas }\end{array}$} & 0.198523 & $2.57995^{\star \star}$ & 0.570724 & 1.157796 & 0.586274 \\
\hline & -0.172206 & -1.044848 & -0.946064 & -1.552769 & -0.746556 \\
\hline \multirow{2}{*}{$\begin{array}{l}\text { Share of population with } \\
\text { garbage collection }\end{array}$} & 0.033902 & -0.150661 & 0.002286 & -0.237639 & 0.10319 \\
\hline & -0.142065 & -0.621317 & -0.345916 & -0.732616 & -0.34773 \\
\hline \multirow{2}{*}{ Political Dummy } & 0.02521 & 0.03396 & 0.038197 & 0.010153 & -0.008776 \\
\hline & -0.018075 & -0.02419 & -0.061215 & -0.055033 & -0.077531 \\
\hline \multirow{2}{*}{ Vaccine } & -0.543554 & $-1.512536^{* *}$ & 2.470055 & 4.813664 & 7.723039 \\
\hline & -0.441443 & -0.709361 & -2.005265 & -4.685936 & -6.377786 \\
\hline Year effects & $\mathrm{x}$ & $\mathrm{x}$ & $\mathrm{x}$ & $\mathrm{x}$ & $\mathrm{x}$ \\
\hline Fixed Effects & & & $\mathrm{x}$ & & \\
\hline Random Effects & & & & $\mathrm{x}$ & $\mathrm{x}$ \\
\hline Number of observations & 105 & 105 & 105 & 105 & 105 \\
\hline
\end{tabular}

Note: robust standard error in parentheses. ${ }^{* *},{ }^{* *}$ and ${ }^{*}$ denote significance at $1 \%, 5 \%$ and $10 \%$ respectively. All variables in logarithm except "Political Dummy". The constant term is always included. No instruments included. 
that both health centers and hospitals have two effects on child mortality: a direct one (by offering health services) and an indirect one (as health centers increase the efficiency of hospitals).

A preliminary point refers to the role of education. When a non-significant interaction term between education and health centers is added (column 5), the effect of health centers disappears; we cannot disentangle the effects of education and health centers then. The impact of the latter (through the interaction with hospitals alone) is reduced to 0.03 .

Most of the controls had the expected sign, but were not significant in the main specification (Table 4, column 3). This has two explanations. First, time variation is low in the four-year span-highlighting the usefulness of the rapid expansion in health centers in this period. Second, some variables have low variation across states as a result of national policies. A noteworthy feature is related to the coefficient of income, which is not significant in any specification. We have two explanations for this. First, the BHS effectively provides medical insurance to the very poor-at least to the extent that it prevents child mortality. Second, an income gain necessary to pull someone above the poverty line is not enough to give access to more sophisticated medical services. Another interpretation is that all the effect of income is captured through access to private insurance, which was quite significant.

Taking into account interaction effects, the total impact of health centers on child mortality varies over time, as the number of available hospitals change. In fact, this elasticity increases in absolute value, suggesting health policy has become more efficient. A similar point is valid for hospitals, which is particularly striking as their number was reduced.

In summary, from the results above, we believe the effect of health centers on child mortality can be split into two components, as was discussed in previous section. First, there is a direct impact. Second, it increases the efficiency of hospitals in treating more serious conditions.

For the sake of robustness, we note that the main results survive when we drop the lags and use current expenditures and general maintenance as instruments for health centers and hospitals. We have three general measures of public expenditures which we use as instruments for the variable health centers: Current expenditures (DC), General maintenance (DCus) and Total cost of government employee salaries (DCP). DCP is included in DCus, which is included in DC; for this reason we use the differences between them. These are general measures of public expenditures, but they do not include public investments, under which the building of new health centers is accounted. They are correlated with health expenditures, as they are also pro-cyclical - but they are not believed to respond to changes in child mortality, as they are not health-related expenditures, and follow political decisions based on other factors. Table 5 reports this additional exercise. 
Table 5. Regression results (Alternative instruments).

\begin{tabular}{cccc}
\hline $\begin{array}{c}\text { Dependent Variable: Child } \\
\text { Mortality (0 - 4 years) }\end{array}$ & $(1)$ & $(2)$ & $(3)$ \\
\hline Health Centers & -4.349267 & -7.594428 & $-8.283170^{* *}$ \\
Hospitals & 4.087912 & 7.789618 & 3.880368 \\
& $-1.897726^{* *}$ & -2.298005 & $-2.445935^{* * *}$ \\
Interaction (Health & 0.599478 & 4.439505 & 0.725788 \\
Centers and Hospitals) & -1.332107 & 0.233974 & $-2.363754^{* *}$ \\
Controls & 1.033075 & 1.933092 & 1.017393 \\
Year effects & $\mathrm{x}$ & $\mathrm{x}$ & $\mathrm{x}$ \\
Fixed Effects & $\mathrm{x}$ & $\mathrm{x}$ & $\mathrm{x}$ \\
Random Effects & & $\mathrm{x}$ & $\mathrm{x}$ \\
Number of observations & 105 & 105 & 105 \\
\hline
\end{tabular}

Note: robust standard error in parentheses. ${ }^{* *},{ }^{* *}$ and ${ }^{*}$ denote significance at $1 \%, 5 \%$ and $10 \%$ respectively. All variables in logarithm except "Political Dummy". The constant term is always included. No instruments included. Controls include all additional regressors present in Table 3 and Table 4.

\section{Final Remarks}

The literature often finds little or no impact of increased health expenditure on health status. Our results show that, when one focuses on mortality rates of children, improving the public health system does have an impact: mortality rates are lower when more health centers are available. This suggests that although overall mortality rates do not respond to changes in the public system, children can be effectively treated in it.

While we have focused so far on health centers, it is well-known that different types of physicians have different impacts on child mortality. Indeed, gynecologists seem to play a major role, which is related to the fact that prenatal care is the most effective in reducing hazards for newborns (Currie \& Gruber, 1996). Despite some preliminary results reflecting this impact, we have not been able to disentangle it effectively from the availability of health centers (which, as mentioned before, are an important workplace for various types of physician).

A delicate point concerns the structure of fixed effects, which were assumed to be uncorrelated with the regressors. A formal way to check this possibility is to run a Hausman test, in which the null hypothesis is the absence of such correlation (so that a random-effects model is indeed more appropriate). Although the null hypothesis was not rejected in any specification of the model, a major problem with the Hausman test is that it relies on a not-too-low variability across time (otherwise, the test statistic is not valid). Although our main variables of interest did change significantly over time, some of the controls did not (such as 
education or income)-most of the variability is across states, not over time. This, in turn, made all fixed-effects estimators non-significant. Future research should implement a robust test to check if these estimators are unnecessary (Hahn et al., 2011). We relate this exactly to the low variability across time of some regressors, such as income and education. Since fixed-effect estimators rely decisively on variation across time, it becomes imprecise. Alternatively, one could build longer series so as to obtain a large variability across time, which could lead to more precise fixed-effect estimates. This is one of the major challenges in this literature as many relevant data series change or are discontinued over time.

\section{Acknowledgements}

We thank Renan Andrade for excellent research assistance.

\section{Conflicts of Interest}

The authors declare no conflicts of interest regarding the publication of this paper.

\section{References}

Auster, R., Leveson, I., \& Sarachek, D. (1972). The Production of Health, an Exploratory Study. In Essays in the Economics of Health and Medical Care (pp. 135-158). Cambridge, MA: NBER.

Currie, J., \& Gruber, J. (1996). Saving Babies: The Efficacy and Cost of Recent Changes in the Medicaid Eligibility of Pregnant Women. Journal of Political Economy, 104, 1263-1296. https://doi.org/10.1086/262059

Fayissa, B., \& Gutema, P. (2005). Estimating a Health Production Function for Sub-Saharan Africa (SSA). Applied Economics, 37, 155-164. https://doi.org/10.1080/00036840412331313521

Gabbe, S., Niebyl, J., Simpson, J., Landon, M., Galan, H., Jauniaux, E., Driscoll, D., Berghella, V., \& Grobman, W. (2016). Obstetrics: Normal and Problem Pregnancies e-Book. Amsterdam: Elsevier Health Sciences.

Glaeser, E. (2011). Triumph of the City: How Urban Spaces Make Us Human (1st ed.). New York: Pan Macmillan.

Grossman, M. (1972). On the Concept of Health Capital and the Demand for Health. Journal of Political Economy, 80, 223-255. https://doi.org/10.1086/259880

Grossman, M. (2017). The Demand for Health: A Theoretical and Empirical Investigation. New York: Columbia University Press. https://doi.org/10.7312/gros17900

Hahn, J., Ham, J., \& Moon, H. (2011). Test of Random versus Fixed Effects with Small within Variation. Economics Letters, 112, 293-297. https://doi.org/10.1016/j.econlet.2011.05.018

Lucas Jr., R. (1988). On the Mechanics of Economic Development. Journal of Monetary Economics, 22, 3-42. https://doi.org/10.1016/0304-3932(88)90168-7

Murray, C. (1994). Quantifying the Burden of Disease: The Technical Basis for Disability-Adjusted Life Years. Bulletin of the World health Organization, 72, 429-445.

Thornton, J. (2002). Estimating a Health Production Function for the US: Some New 
Evidence. Applied Economics, 34, 59-62. https://doi.org/10.1080/00036840010025650 World Bank (2020). World Development Indicators. Washington DC.

Zweifel, P., Breyer, F., \& Kifmann, M. (2009). Health Economics. Berlin/Heidelberg: Springer Science \& Business Media. https://doi.org/10.1007/978-3-540-68540-1 


\section{Appendix}

\section{A1. Specification and Measurement of Variables}

This section discusses the variables included in the model. Most of the series we used can be found in the PNAD-SIDRA database of the IBGE (Brazilian Geography and Statistics Institute) and the DataSus database of the Brazilian Health Ministry.

\section{A1.1. Brazil's DataSus System}

DataSus is the database of the Information Technology Department of the SUS, created by a federal decree in 1991. Employees and some basic equipment of the DataSus system were transferred in from DataPrev, the Social Security Technology and Information Company ("Empresa de Tecnologia e Informacoes da Previdencia Social", the public company responsible for the data processing of the Brazilian Social Security System.). The principal technology resources for the creation of the database were transferred to DataSus by the predecessor health service system, Inamps (Instituto de Assistencia Médica e PrevidÍncia Social Medical and Social Security Assistance Institute). Until the creation of SUS, in the 1990s, Inamps was responsible for all public healthcare, but provided it only to those workers who contributed to the Social Security system. Social Security is now under the responsibility of the National Social Security Institute (Instituto Nacional do Seguridade Social, or INSS), while public healthcare (which is now universal) is the exclusive responsibility of the SUS.

Until 1998, DataSus operated with low funding and an insufficient structure. In that year it was transferred to the direct federal administration, under management of the Executive Department of the Health Ministry (Ministério da Saúde, or MS). With the organizational restructuring of the MS in 2002 a clearer structure was established for DataSus, with a more precise definition of its competencies, which include managing and operating the whole of the health information system, and deciding guidelines, rules and standards for capture and transfer of information on health in the country.

The database of DataSus offers indicators of health per se (epidemiological and mortality information, data on immunizations, vital statistics, etc.) and also information on demographics, social and economic conditions and sanitation conditions. It also gives information about the healthcare network through the National Registry of Health Establishments (Cadastro Nacional de Estab-elecimentos de Saúde, or CNES), which contains data on the physical resources (hospitals, health centers and other health units) and the country's human resources (doctors, nurses and other health professionals). Finally, DataSus has financial information on the funds of the National Health Fund (Fundo Nacional de Saúde, or FNS) that are transferred to the municipalities, the credits to health service providers, and the public health budgets declared by the States, the Federal District, and the Municipalities.

DataSus, thus, represents something of a census of Brazil's health system, 
since it contains complete information about the resources available and the health data of Brazil's population.

\section{A1.2. PNAD}

The National Homes Sample Survey (Pesquisa Nacional por Amostra de Domicílios, or PNAD) is an annual survey carried out by the Brazilian Geography and Statistics Institute ("Instituto Brasileiro de Geografia e Estatistica", or IBGE), which aims to maintain a permanent investigation on the general characteristics of the Brazilian population, and in particular on aspects such as education, work, income and housing. As well as this information, which is available in every edition of the PNAD, other characteristics (such as migration, fertility, marriage statistics, health, food security, etc.) are also investigated at variable intervals, in accordance with the country's needs for information, and this information is published in supplementary volumes to the principal survey. The PNAD is carried out throughout the whole of Brazil's territory, in both the rural and the urban areas. The rural areas of Rondônia, Acre, Amazonas, Roraima, Pará and Amapá were included for the first time only in 2004.

The PNAD is carried out by means of a complex sampling of homes, carried out in three stages. In the first stage, municipalities (primary units) are selected, which are classified as self-representative or non-self-representative. (This classification depends on the scale of the municipality's population. Very highly populated municipalities (based on the last Census prior to the PNAD of the year in question), or those that are part of the metropolitan areas, are considered to be self-representative.) The probability of self-representative municipalities appearing in the sample is specified as 1 , whereas the others are selected (with reposition) with a probability proportional to their population. The secondary units are the census sectors of the municipalities of the sample and are also selected (with reposition) with a probability proportional to the number of homes existing in the last prior census. In the final stage, the homes in each census sector of the sample are selected with equal probability.

Due to its complex sampling plan, statistics obtained based on the PNAD data should take into account the sample weighting of each observation. However, the data that we use were obtained from the summary of indicators of the PNAD for the years 2006 to 2009 published by the IBGE. These indicators refer to values by state, constructed by the IBGE on the basis of individual observations, and take the sampling plan of the PNAD into account in their calculation.

\section{A1.3. Description of the Variables}

Health centers (DataSus): We include the following types of health centers: Health Posts; Health Centers/Basic Health Units; Polyclinics; General and Specialized Hospitals; Mixed Units; General and Specialized First Aid Units; Family Health Support Centers; Specialized Clinics/Specialized Outpatient Clinics; Isolated Natural Birth Centers; and Rapid Healthcare Units. The names given correspond to the nomenclature of the CNES32. These units offer differing types of 
outpatient and emergency care, from basic care and childcare (Basic Health Units and Health Posts), to procedures of medium and high complexity (First Aid Units and Hospitals). The degree of complexity of each one of these units follows a hierarchy defined by the Health Ministry. However, all the units included provide care to children and/or pregnant mothers and may be seen as substitutes.

Child mortality (DataSus): We use the ratio between child deaths before age five and the total population aged five years or less.

Income (Ipeadata): For income data, we used the proportion of poor people in the population of each state. For this calculation, we took the quotient of the number of people in homes with total household income per capita below the poverty line, divided by the population of each State, both obtained from PNAD/IBGE. The value of the poverty line considered here is twice the value of the extreme poverty line, an estimate of the value of a basket of foods with the minimum of calories necessary to support a single person adequately, based on recommendations of the FAO (UN Food and Agriculture Organization) and the WHO (World Health Organization).

Education (PNAD-SIDRA/IBGE): The percentage of people aged 10 or more, per State, with up to four completed years of schooling.

Private Insurance (DataSus): Percentage of the population of each State covered by private healthcare plans. Data obtained in the DataSus based on information of the National Supplementary Healthcare Agency (ANS).

White (PNAD-SIDRA/IBGE): In each State, the number of people stating themselves to be of the white race, as a percentage of the State's population.

Smokers (Vigitel survey of the MS): Number of individuals who are smokers as a percentage of the number of individuals interviewed. A person responding affirmatively to the question "Do you smoke?" was considered to be a smoker, independently of the number of cigarettes, frequency, or duration of the smoking habit. Vigitel (the Telephone Vigilance Survey for Risk Factors and Protection from Chronic Illnesses) is a survey carried out annually since 2006 by the Health Ministry, aiming to measure the prevalence of risk factors and protection for non-transmissible illnesses in the Brazilian population. It monitors adults (age 18 or over) resident in homes with a fixed telephone line in the capitals of the 26 Brazilian States, and the Federal District, and carries out about 54,000 interviews each year. The proportions are calculated without taking into account cases of non-reply and not-applicable, and the percentages are weighted to adjust the social-demographic distribution of the Vigitel sample to the distribution of the adult population of each city in the Demographic Census of 2000, and to take into account the population weighting of each city.

Garbage collection (PNAD-SIDRA/IBGE): Percentage of permanent private homes that have access to direct garbage collection in the State.

Urbanization (PNAD-SIDRA/IBGE): Percentage of the population of each State that live in urban areas. 
Political dummy: A dummy variable to indicate political alignment of the government of the State in question with the political party of the federal government in the period 2006-2009, with value 1 for States where the Governor is of the same political party as the federal government's support base. The data for the political affiliation of each Governor were obtained from the websites of the States.

Immunization (DataSus): A total for vaccination coverage that represents a mean resulting from the sum of all the vaccines.

Population (PNAD-SIDRA/IBGE): Population resident in each State, by age group. Data obtained from the PNAD for each year. 